\title{
THE RELATION OF POSTSYNAPTIC GEOMETRY TO THE NUMBER OF PRESYNAPTIC AXONS THAT INNERVATE AUTONOMIC GANGLION CELLS ${ }^{1}$
}

\author{
DALE PURVES AND RICHARD I. HUME
}

Department of Physiology and Biophysics, Washington University School of Medicine, St. Louis, Missouri 63110

\begin{abstract}
We have studied the shape of rabbit ciliary ganglion cells in relation to the number of axons that innervate each neuron. Adult ganglion cells receive synapses from one to seven different preganglionic axons. Some neurons lack dendrites altogether, whereas others have complex arborizations of up to eight primary dendrites. The neurons that receive all of their synaptic contacts from a single preganglionic axon usually have no dendrites; on the other hand, multiply innervated ganglion cells receive synapses from a number of different axons that increases in proportion to the number of primary dendrites that they possess. A possible explanation of these results is that individual ciliary ganglion cells comprise a number of separate spatial domains, each of which is largely constrained to receive innervation from a single preganglionic axon.
\end{abstract}

An important aspect of the pattern of innervation established during development is the number of different axons that contact each target neuron. This number varies from one to many thousand and sets an upper limit on a nerve cell's ability to integrate information. The factors that determine the number of axons that innervate individual neurons are not known.

In previous studies of mammalian autonomic ganglia in which the number of axons innervating individual neurons was assessed (see Purves and Lichtman, 1980, for a review), a relation was noted between the number of axons in synaptic contact with various sorts of cells and their anatomical complexity. For example, rat submandibular ganglion cells are generally innervated by a single preganglionic axon and lack a significant dendritic arborization (Lichtman, 1977, 1980). In contrast, guinea pig superior cervical ganglion cells receive synapses from about a dozen different axons (Njå and Purves, 1977) and have a substantial number of dendrites (McLachlan, 1974; Purves, 1975). This apparent correlation between cellular geometry and the number of different axons that contact neurons is difficult to interpret because the neurons in question are in different ganglia, have different functions, and were studied in different species. Therefore, we wanted to investigate, in a single ganglion, the

\footnotetext{
${ }^{1}$ We wish to thank $\mathrm{T}$. A. Woolsey for the use of the computer facilities and J. T. Buchanan and M. L. Dierker for helpful advice. We are also grateful to J. E. Heuser, C. C. Hunt, D. A. Johnson, J. W. Lichtman, E. Rubin, J. R. Sanes, and D. J. Wigston for critical comments. Our work was supported by United States Public Health Service Grant NS 11699, a grant from the Muscular Dystrophy Association, and National Institutes of Health Training Grant 5 T 32 NS 07071.
}

relation between the number of axons that innervate each cell and neuronal geometry. In the present report, we have carried out such a study in the rabbit ciliary ganglion, where each neuron receives synaptic contacts from a small, but variable, number of different axons (Johnson and Purves, 1980, 1981). The results of our analysis show that the number of different inputs that a neuron receives is closely related to the number of dendrites that it possesses. This finding raises the possibility that one function of dendrites is to regulate the number of different axons that innervate nerve cells.

Some of these results have been presented in abstract form (Hume and Purves, 1980).

\section{Materials and Methods}

Electrophysiological techniques. Young adult rabbits (New Zealand albinos, 12 to 18 weeks old, 2.5 to $4.0 \mathrm{~kg}$ ) were anesthetized with pentobarbital $(50 \mathrm{mg} / \mathrm{kg}$ intravenously) and perfused through the heart with 1 liter of saline to wash out the blood. After removing portions of the frontal bone, both the right and left ciliary ganglia were dissected, along with 3- to 4-mm lengths of the preand postganglionic nerves (Johnson and Purves, 1981). Isolated ganglia (Fig. 1) were placed in a transparent chamber and superfused continuously with oxygenated saline solution at room temperature (see Johnson and Purves, 1981). The $\mathrm{Ca}^{2+}$ concentration in this fluid was raised to $5 \mathrm{mmol} / \mathrm{liter}$ to improve the stability of intracellular recordings.

The oculomotor nerve, which carries the preganglionic axons, was drawn into a close fitting suction electrode, the tip of which was advanced to about the level of the superior rectus branch (see Fig. 1). The postganglionic 


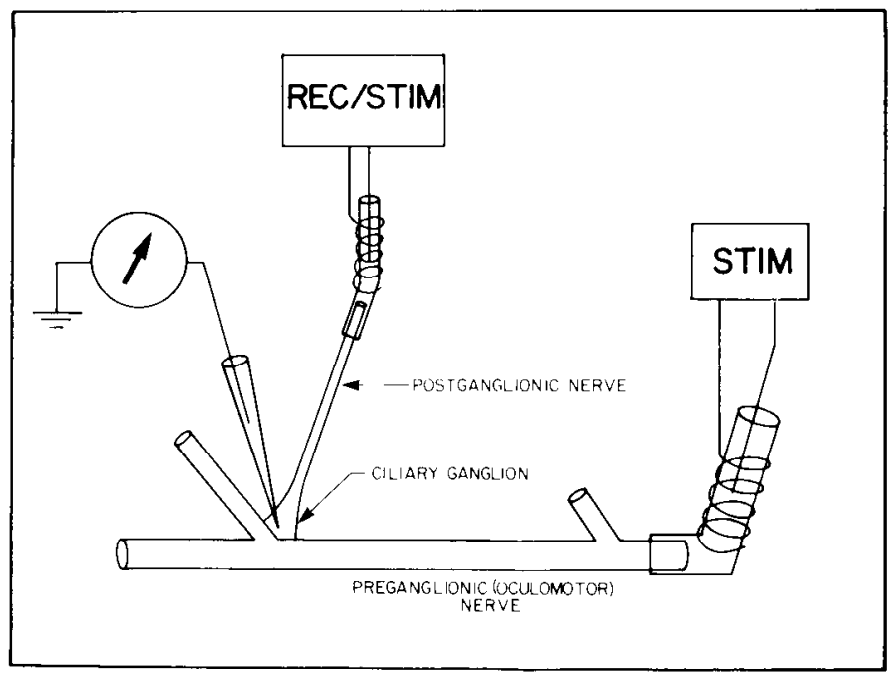

Figure 1. Diagram of the isolated rabbit ciliary ganglion preparation. Preganglionic axons in the oculomotor nerve were stimulated at about the level of the superior rectus branch while we recorded intracellularly from ganglion cells with an HRP-filled microelectrode. Compound action potentials were monitored in the postganglionic nerve to assure the integrity of the preparation. The postganglionic nerve could be stimulated via the suction electrode to determine whether a ganglion cell sent its axon into this nerve.

nerve was drawn into a second suction electrode. By recording the postganglionic compound action potential in response to stimulation of the preganglionic nerve, the integrity of the preparation was monitored throughout each experiment.

Individual ganglion cells were impaled with glass microelectrodes filled by capillarity with a $4 \%$ solution of horseradish peroxidase (HRP, Sigma type VI) in $0.2 \mathrm{M}$ potassium acetate buffered to $\mathrm{pH} 7.6$ with $0.05 \mathrm{M}$ Tris (Trizma, Sigma). Electrode resistances were between 50 and 90 megohms. An impalement was considered satisfactory if the neuron gave an action potential of $60 \mathrm{mV}$ or more in response to a brief depolarizing current pulse injected through the microelectrode by means of a bridge circuit.

For each neuron that met this criterion, we gradually increased the strength of the stimulus applied to the preganglionic nerve $(0.4 \mathrm{msec}$, up to $50 \mathrm{~V})$. The number of different axons making synaptic contact with the impaled cell was estimated by repeated observation of the number of increments in the postsynaptic response as the stimulus strength was increased (Fig. 2). 'The limitations of this method have been discussed elsewhere (Lichtman, 1977, 1980; Lichtman and Purves, 1980); briefly, this approach may underestimate the number of inputs because of (1) shunting, (2) nonlinear summation, (3) threshold similarities, and (4) quantal variation. Discrimination of suprathreshold responses was enhanced by causing the postsynaptic potentials to occur during the refractory period of a directly elicited action potential (Purves, 1975). In this way, we could eliminate regenerative responses that otherwise would be superimposed on the postsynaptic potentials. It is evident in Figure 2 that some increments in the postsynaptic response are much larger than others (see Johnson and Purves, 1981). Despite this variability, for the purpose of the present analysis, we treated all increments equally.

Finally, the postganglionic nerve was stimulated to test each ganglion cell for antidromic activation.
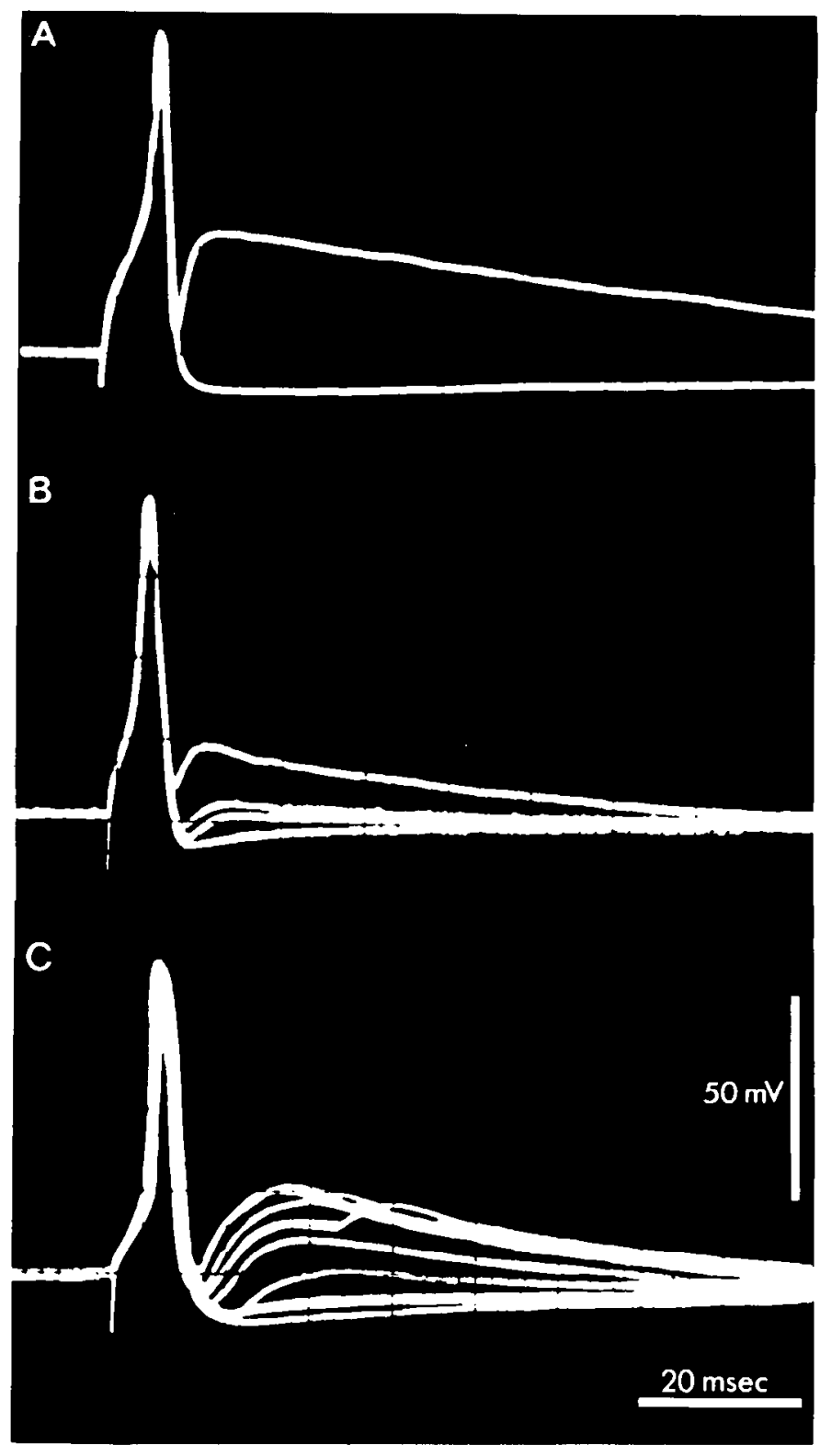

Figure 2. Examples of the method used to estimate the number of axons innervating each ganglion cell. The postsynaptic potentials were timed to occur during the refractory period of a directly elicited spike. In $A$, a single, large, all-ornone synaptic response was evoked at a given level of preganglionic stimulation; no change in this response was observed at greater stimulus intensities. This indicates innervation by a single axon. In $B$, graded preganglionic stimulation repeatedly gave rise to three steps in the postsynaptic response, indicating innervation by three different axons. In $C$, seven different postsynaptic steps were elicited. Note the latency shift of one of the responses at higher stimulus intensities. Two or more traces are superimposed in each panel; the traces have been retouched for clarity. The geometry of each of these neurons is shown in subsequent figures. 
Histological techniques. Following electrophysiological determination of the number of different axons that contacted a cell, HRP solution was injected into the impaled neuron by applying pressure $\left(5\right.$ to $\left.9 \mathrm{~kg} / \mathrm{cm}^{2}\right)$ to the back of the microelectrode for 3 to $20 \mathrm{~min}$ (Muller and McMahan, 1976). Only two or three widely separated cells were injected in any one ganglion so that we could recognize unambiguously each of the injected cells and its processes. After waiting 1 to $4 \mathrm{hr}$ to allow the enzyme to diffuse throughout the processes of the injected neuron, the HRP was demonstrated by a modification of the procedure described by Hanker et al. (1977). Unfixed ganglia were cleaned of surrounding connective tissue, pinned flat on plastic resin, and covered with $10 \mathrm{ml}$ of a $0.2 \mathrm{~m}$ Tris buffer ( $\mathrm{pH} 7.6$ ) to which had been added $5 \mathrm{mg}$ of $p$-phenylenediamine, $10 \mathrm{mg}$ of pyrocatechol, and 0.01 $\mathrm{ml}$ of $30 \%$ hydrogen peroxide. After 10 to $20 \mathrm{~min}$ incubation at room temperature, the ganglia were rinsed with saline and fixed overnight in a formaldehyde/glutaraldehyde solution (Karnovsky, 1965). Ganglia were dehydrated in a graded series of ethanol solutions, cleared in methyl benzoate, and mounted between two coverslips so that the stained neurons could be viewed from either surface.

Of the 157 neurons that we attempted to fill with HRP, 56 were rejected becausc of inadequate staining, leaving a sample of 101 cells. The absence of an identifiable axon (see "Results") was the criterion of unacceptable staining. We doubt that the rejected cells lacked axons, since stimulation of the postganglionic nerve elicited antidromic action potentials in most of these neurons. The axons of successfully injected cells usually extended 500 $\mu \mathrm{m}$ or more; it seems likely, therefore, that most dendrites were filled completely since their linear extent was usually less than this distance (mean length $=258 \mu \mathrm{m}$ ). Finally, the mean diameter of labeled neurons was the same $(35 \mu \mathrm{m})$ as the average diameter of unlabeled neurons (Johnson and Purves, 1981); therefore, our sample of labeled cells was probably representative of the ganglion cell population as a whole.

For the purpose of illustration, camera lucida drawings of the successfully stained neurons were made at a total magnification of $\times 300$. For quantitative analysis of neuronal geometry, the dendrites of injected neurons were traced in three dimensions with a computer-assisted microscope (Wann et al., 1973). In this way, we could determine accurately the number of dendrites for each neuron, the length of each dendrite, the number and location of dendritic branch points, and the total extent of the dendritic arbor. The axon of each cell was identified (see "Results") and excluded from these calculations. A primary dendrite was defined as a process other than the axon extending more than $5 \mu \mathrm{m}$ from the cell body. As can be seen in Figures 6 to 9, most dendrites run a much longer course. In neurons with complex arborizations, there was some tendency for dendritic processes to arise from adjacent regions of the cell soma (see Figs. 8 and 9, for example). Processes arising from a single point were considered to be separate primary dendrites; processes arising from a common stem greater than $5 \mu \mathrm{m}$ in length were treated as branches of a single primary dendrite.

\section{Results}

\section{Distinction between axons and dendrites}

Each of the 101 neurons that we successfully injected with HRP had a single long process judged to be the axon because of $(a)$ its smooth contour, $(b)$ its lack of branches, and (c) its emergence and long course in the postganglionic nerve (Fig. $3 A$ ). 'This last criterion was met in 79 of the 101 cells in the series. In the other 22 , identification of the axon was based on only the first two criteria. An antidromic action potential was elicited nonetheless by postganglionic stimulation in 9 of these cells. The postganglionic portion of these axons presumably was not marked because of a particularly long intraganglionic course. The tortuous and often bizarre route taken by many axons before running into the postganglionic nerve is evident in Figures 5 to 9 . The remaining 13 neurons whose axons could not be followed into the major postganglionic nerve were not driven antidromically by postganglionic stimulation. In several of these cells, the axon could be followed into one of the small nerve twigs that sometimes emerged from the ganglion or into the oculomotor nerve. Whether these unusual routes of exit represent alternative pathways to the globe, or innervation of other targets, is not known.

In contrast to axons, dendrites were distinguished by branching of the primary process into secondary and tertiary segments (Figs. 5 to 9), by numerous short processes arising from the dendritic shaft (Fig. $3 B$ ), and by failure to extend beyond the proximal portion of the postganglionic nerve. In 23 cells, the axon and a dendrite arose from a common process (see Figs. 6 to 9). For purposes of dendritic analysis (see below), the axon was ignored, and the common process was treated as part of the dendrite.

\section{Geometry of singly and multiply innervated ganglion cells}

Each of the neurons that we impaled showed a suprathreshold response to preganglionic (oculomotor) nerve stimulation. In agreement with an earlier study (Johnson and Purves, 1981), some neurons showed a single all-or-none postsynaptic response, while others showed as many as seven discrete steps in the postsynaptic potential as the strength of preganglionic stimulation was increased gradually (Fig. 4). Since there are few, if any, connections between ganglion cells (Johnson and Purves, 1981), the number of steps in the postsynaptic response reflects the number of different preganglionic axons that innervate each ganglion cell.

Geometry of singly innervated cells. Twenty-nine neurons showed a unitary, all-or-none response to preganglionic stimulation (Fig. $2 A$ ) and, therefore, were judged to be singly innervated. 'Twenty of these 29 cells lacked dendrites altogether, while the other 9 had only rudimentary dendritic arborizations (Fig. 5).

Geometry of multiply innervated cells. Almost all of the ganglion cells that received synaptic contacts from more than one preganglionic axon had one or more dendrites. In general, the number of these processes increased in direct proportion to the number of innervating axons (Figs. 6 to 9). Thus, neurons that showed two 

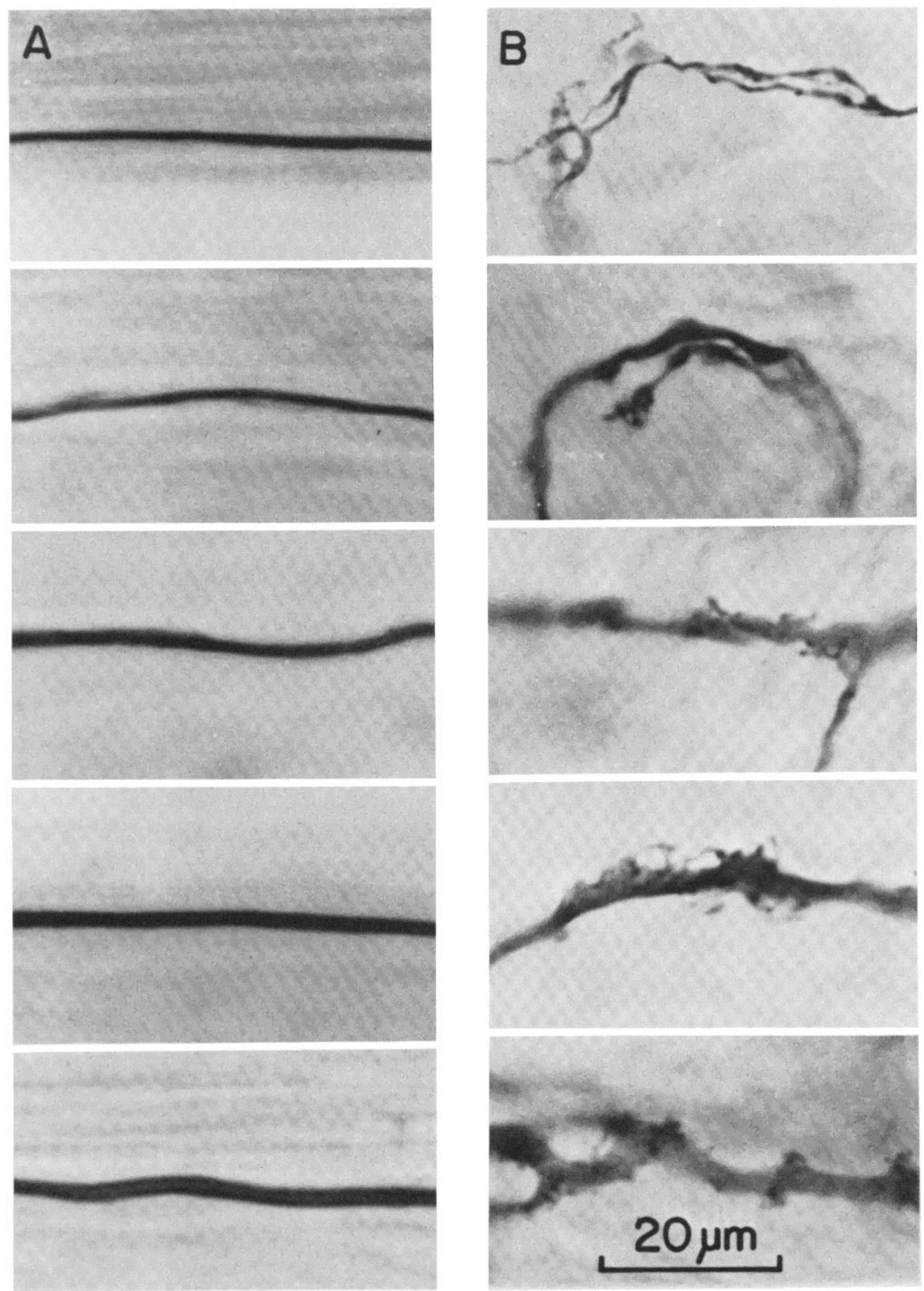

Figure 3. Processes arising from ciliary ganglion cells labeled with HRP. A, Examples of HRP-stained axons. Axons were smooth and unbranched. $B$, Examples of HRP-stained dendrites. Major branches were observed frequently; in addition, numerous short processes were often present in the immediate vicinity of the dendritic shaft. Such short processes were too small to be shown in the subsequent camera lucida drawings (Figs. 5 to 9); neither were these local processes included in the quantitative analysis of dendritic length and branching. Similar fine processes also arose from many cell somata. 


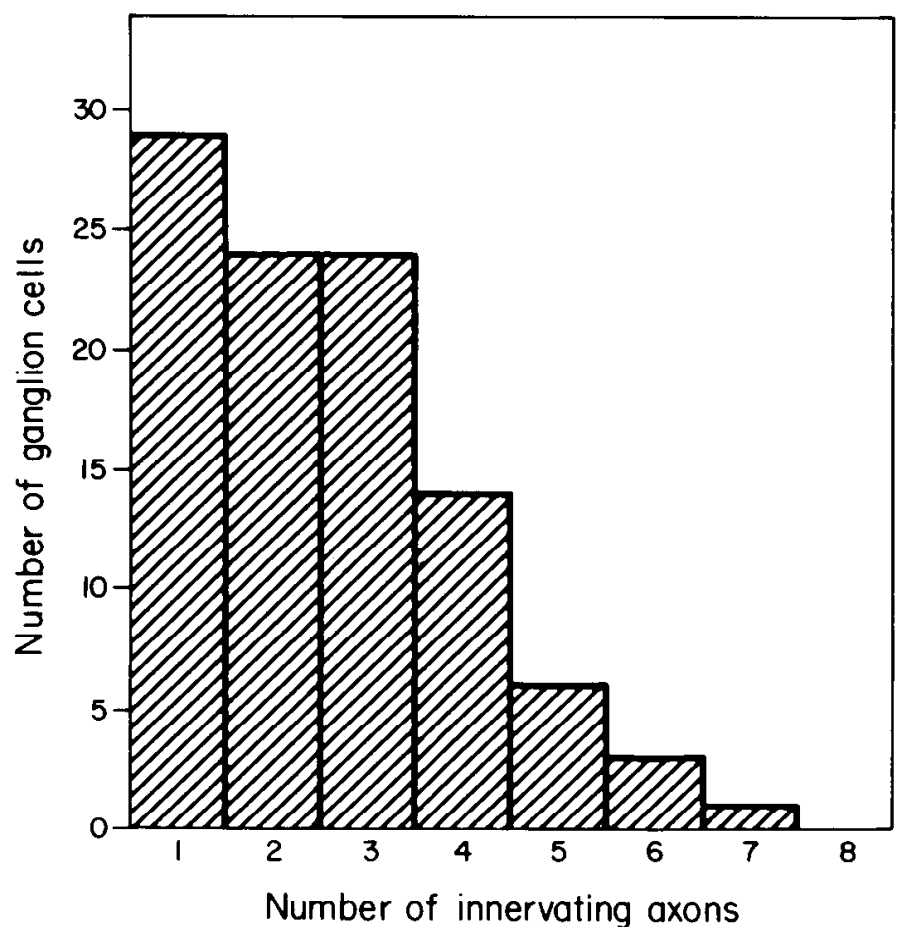

Figure 4. Histogram showing the distribution of the number of neurons innervated by different numbers of axons in the sample of 101 cells successfully injected with HRP after electrophysiological study. The average number of axons innervating each cell was 2.6 .

steps in their postsynaptic response had less complex dendritic arbors (Fig. 6) than neurons receiving synapses from three (Fig. 7) or four (Fig. 8) different preganglionic axons. Ganglion cells receiving synapses from five to seven different axons had the most intricate geometries in the series (Fig. 9).

The correlation between the number of innervating axons determined electrophysiologically and the number of primary dendrites arising from each neuron is summarized in Figure 10. On the average, the number of primary dendrites arising from a neuron increased in a one-to-one manner with the number of different innervating axons (Fig. 10B). Other aspects of neuronal geometry which increase in proportion to the number of axons that innervate a ganglion cell are the total length of its dendritic arbor, the number of branch points in the dendritic arbor, and the total number of terminal dendritic branches (Table I). The size of labeled cell bodies, however, does not vary systematically as a function of the number of innervating axons (Table I).

\section{Discussion}

Our principal finding is that neurons which presumably share the same or a similar function within the same ganglion show a striking correlation between the number of different axons that innervate them and their cellular geometry: Cells that lack dendrites are generally innervated by a single axon, whereas neurons with increasing numbers of primary dendrites receive innervation from a proportionally greater number of different axons.
One explanation of these results might be that the number of different axons that innervate a neuron is related to the surface area available for synaptic contacts. In this view, more preganglionic axons innervate cells with dendrites simply because these processes provide additional synaptic sites. Several aspects of our results, however, are difficult to understand on this basis. First, ciliary ganglion cells that have no dendrites almost invariably receive all of their synapses from the terminals of a single axon (see also Lichtman, 1977, 1980). Conversely, neurons that possess one or more dendrites are endowed with the capacity to receive terminals from more than one axon, not simply the capacity to receive more synapses. While it would not be surprising if a more highly branched neuron received a greater number of synaptic contacts, there is no obvious reason why these synapses should arise from a proportionally greater number of different axons in the highly ordered way that we have observed. Secondly, the dendrites of many cells ramify throughout the ciliary ganglion (Figs. 5 to 9) and, presumably, come near the branches of many of the 40 or so preganglionic neurons that supply the ganglion (Johnson and Purves, 1981). Yet, these ganglion cells are innervated by only a few preganglionic axons (2.6, on the average). Moreover, many ganglion cells have several times more terminal dendritic segments than they do inputs (Table I). Taken together, these observations indicate that simply adding length or branches to a dendrite does not necessarily allow it to make synaptic contact with additional preganglionic axons. Rather, substantial portions of the dendritic arbor must frequently remain associated with a particular preganglionic axon or set of axons.

An alternative hypothesis that may provide a more satisfactory explanation of our results is that individual neurons comprise a number of spatial domains, each of which is largely constrained to receive innervation from the terminals of a single presynaptic axon. In this view, the difference between singly and multiply innervated neurons is not primarily a function of surface area but of the number of domains. The approximately one-to-one relationship between the number of different axons innervating a cell and the number of primary dendrites suggests that each primary dendrite and its subsidiary branches provides one additional domain. For cells that lack dendrites, the cell body (and possibly the proximal axon) provides a single domain within which innervation by more than one axon is not allowed.

Although the hypothesis of neuronal domains fits our results quite well on the average (Fig. 10B), a few neurons without dendrites received innervation from a second axon, and some neurons with dendrites were innervated by a number of axons that was larger or smaller than the sum of their possible domains (primary dendrites plus the cell body) (Fig. 10A). Part of this variation may arise from our methods. For example, the number of axons contacting multiply innervated ganglion cells may be underestimated. On the other hand, this variation may reflect actual patterns of innervation that require qualification of the idea of neuronal domains. For instance, the constraint provided by each domain may not be 


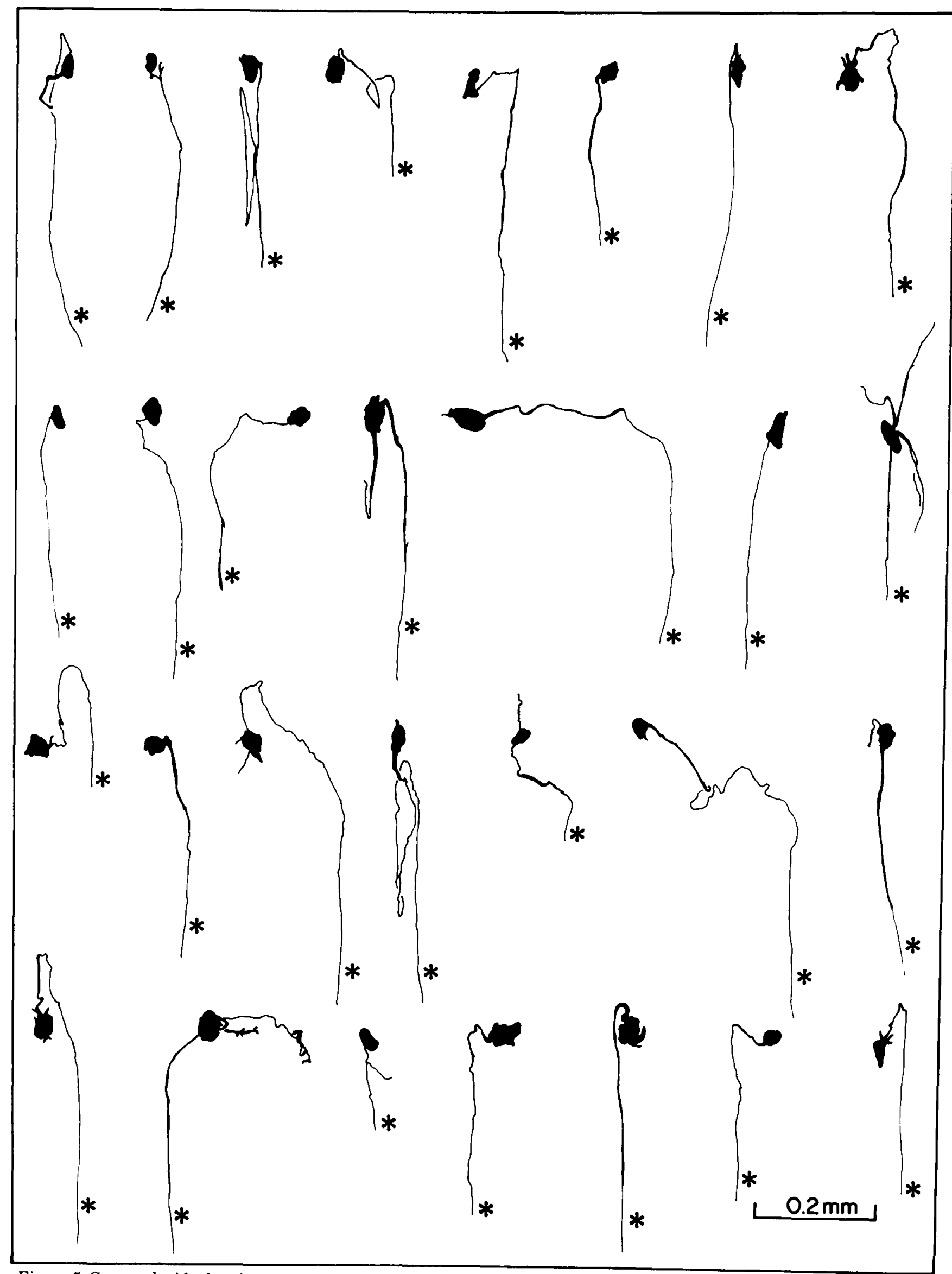

Figure 5. Camera lucida drawings of the 29 ganglion cells that, by electrophysiological criteria, received innervation from only one preganglionic axon. The response shown in Figure $2 A$ was obtained from the fifth cell from the left in the top row. In this and subsequent figures, asterisks indicate the axon of each cell; in many cases, the axon could be followed far beyond the length
shown. 


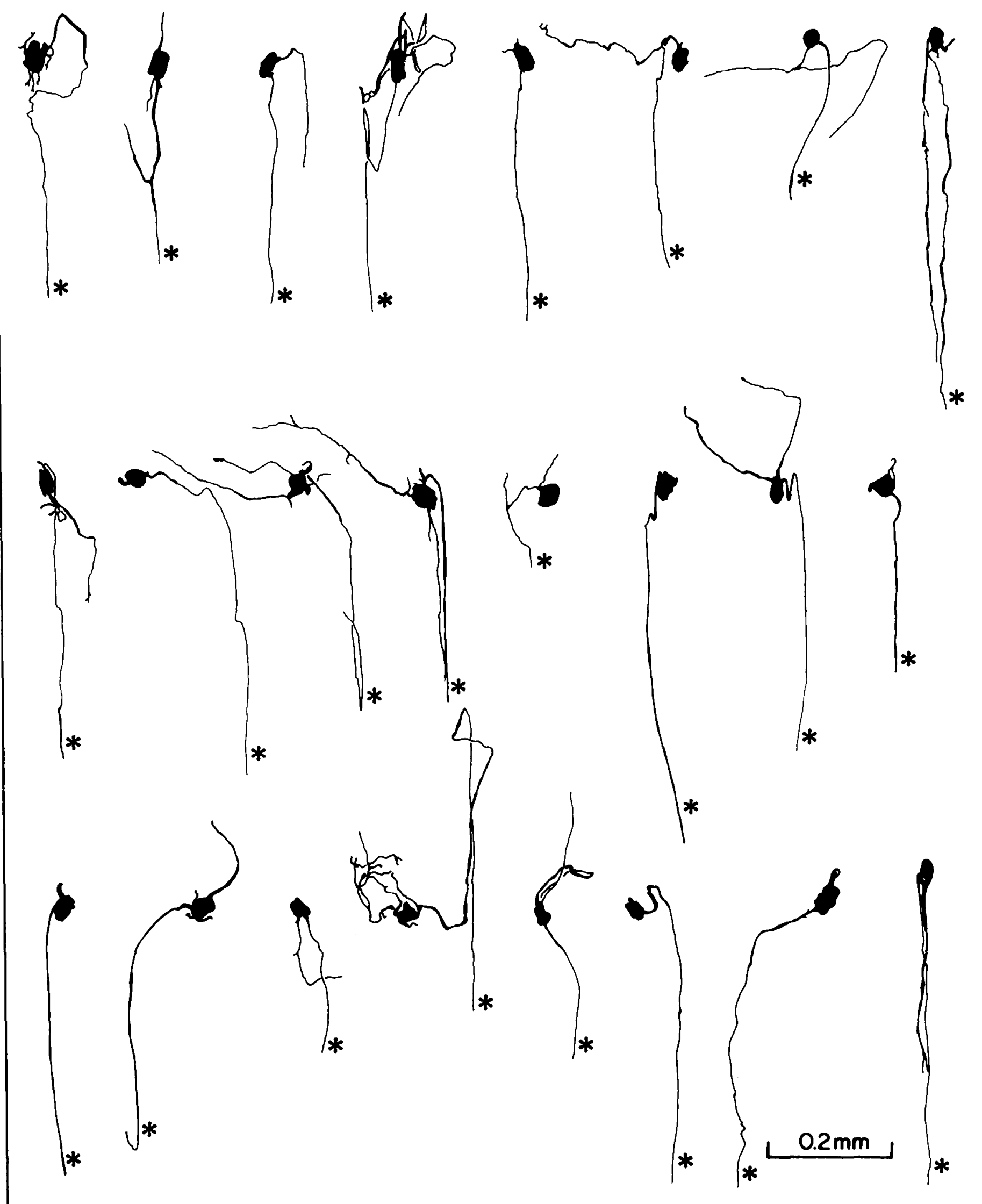

Figure 6. Camera lucida drawings of the 24 ganglion cells that, by electrophysiological criteria, received innervation from two different preganglionic axons. 


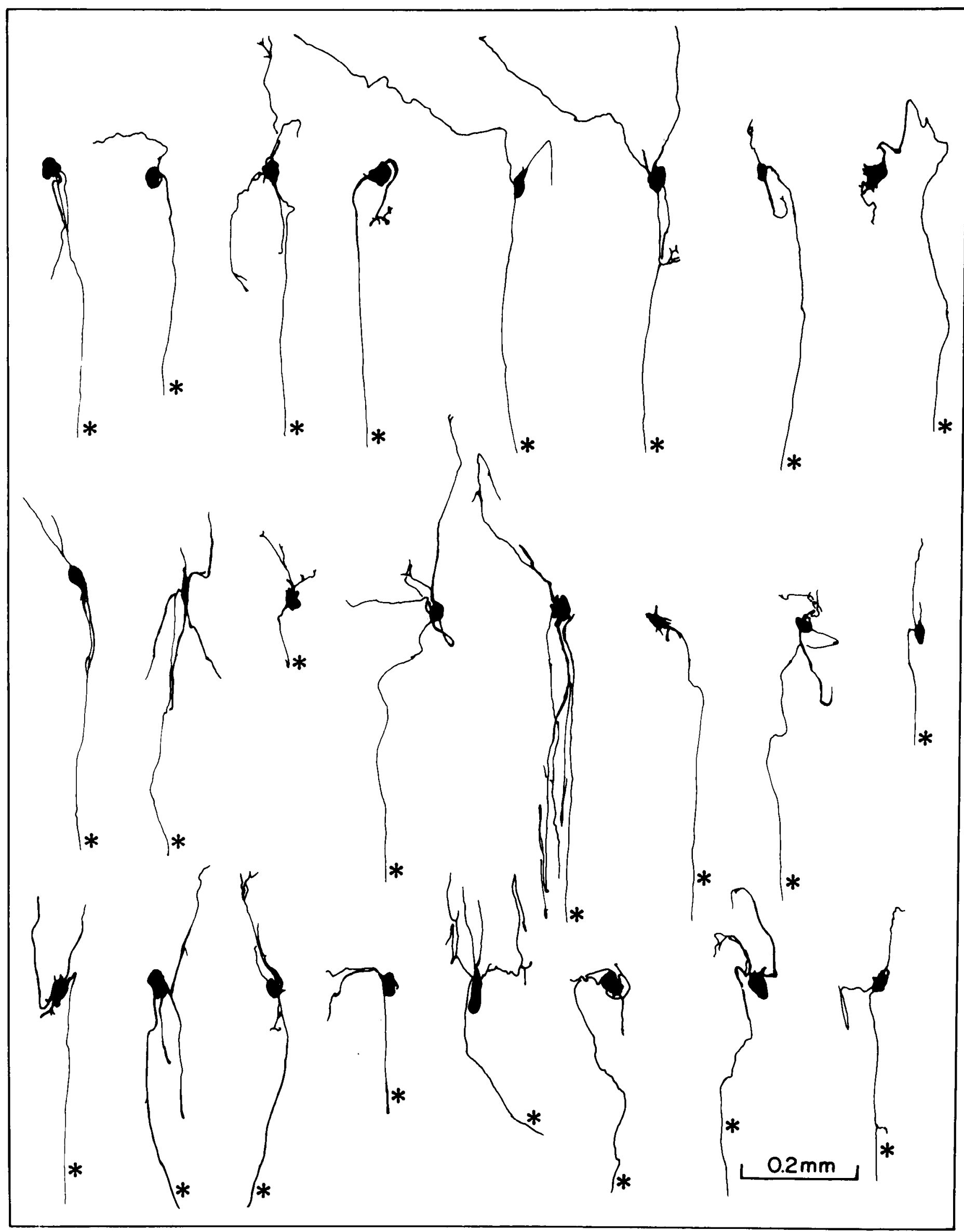

Figure 7. Camera lucida drawings of the 24 neurons that, by electrophysiological criteria, received innervation from three different preganglionic axons. The response shown in Figure $2 B$ was obtained from the second cell from the right in the top row. 


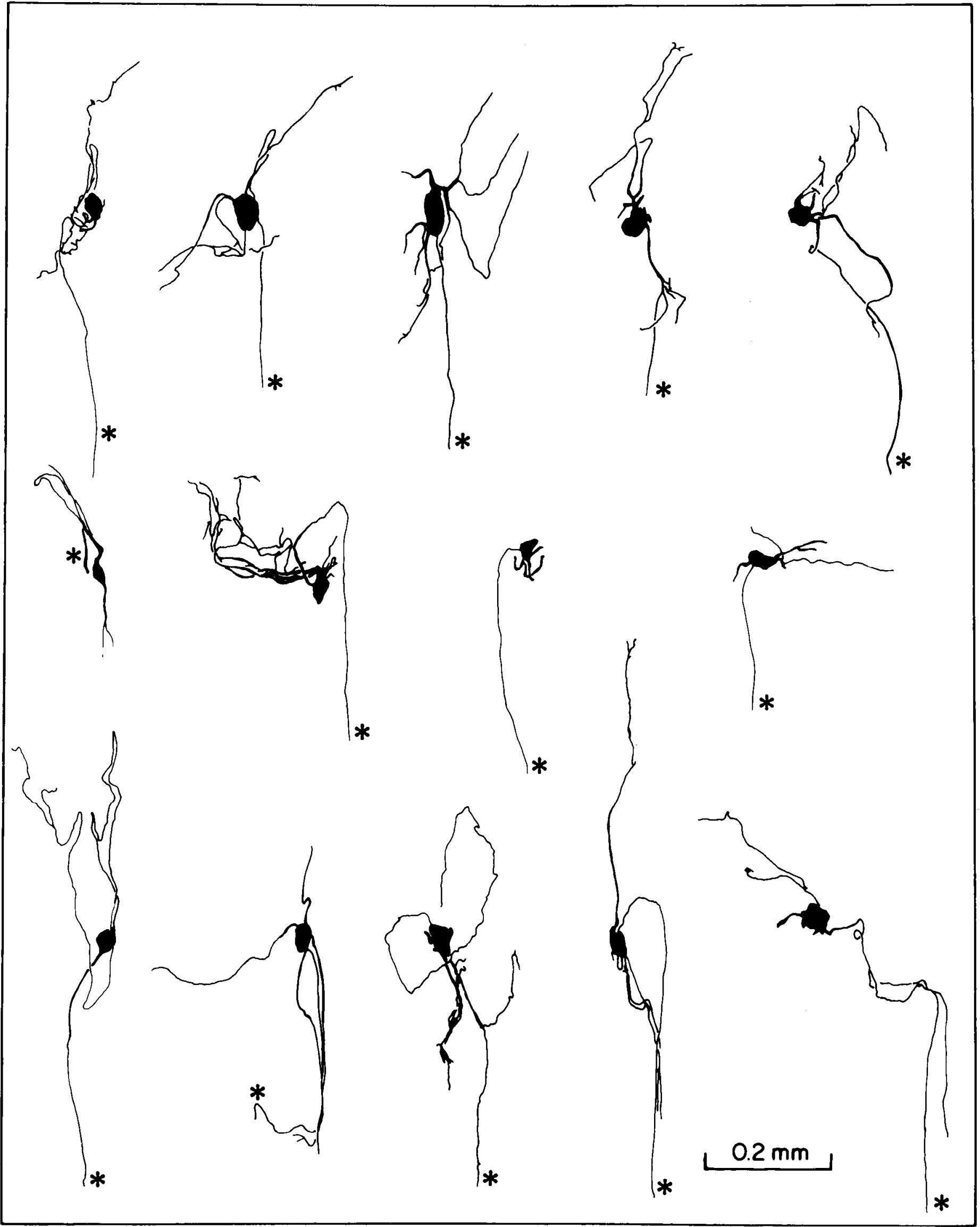

Figure 8. Camera lucida drawings of the 14 cells that, by electrophysiological criteria, received innervation from four different axons. 


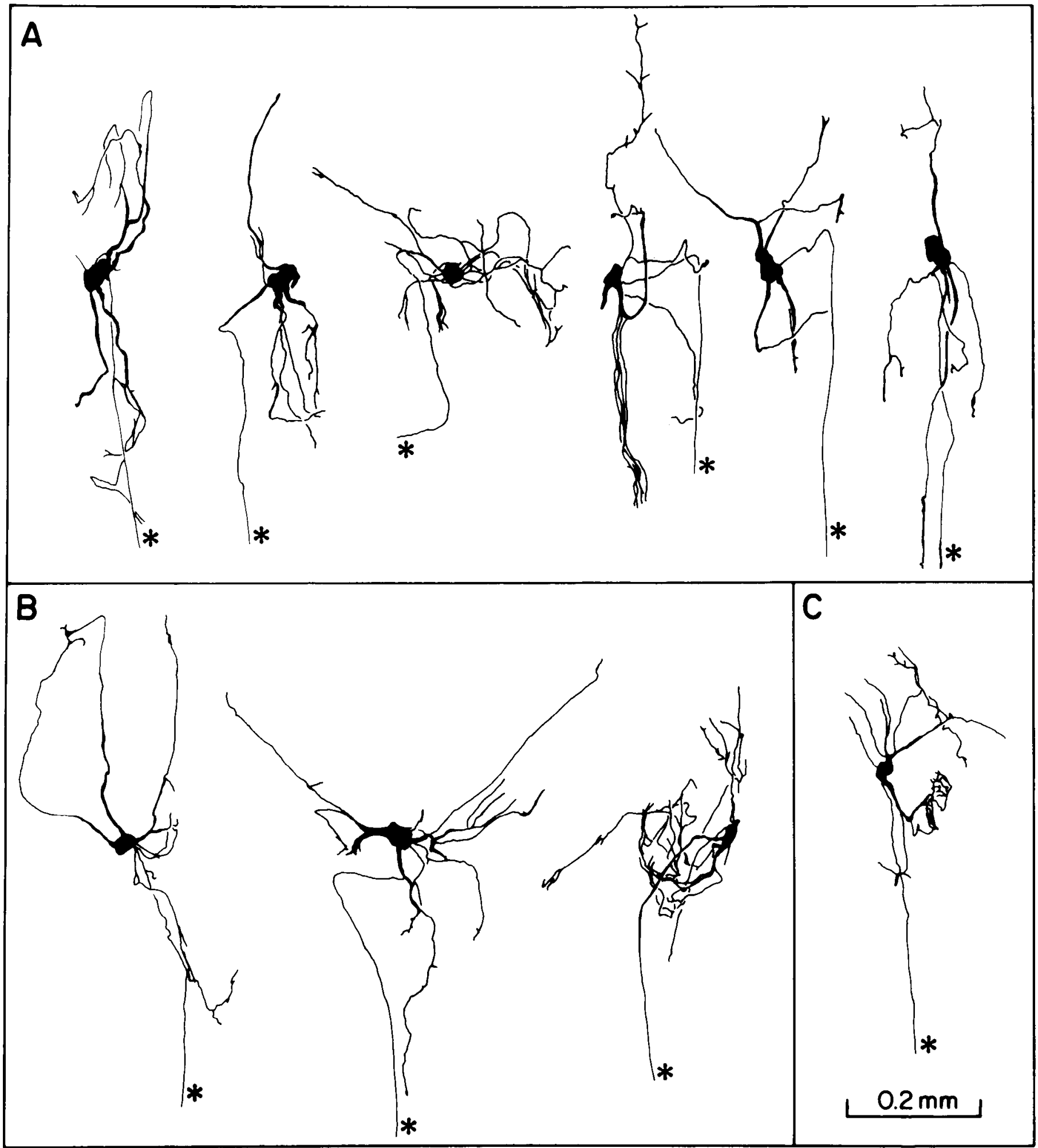

Figure 9. Camera lucida drawings of those ganglion cells that, by electrophysiological criteria, received innervation from five $(A)$, six $(B)$, or seven $(C)$ different axons. The response shown in Figure $2 C$ was obtained from the ganglion cell drawn in $C$. Viewed from the dorsal or ventral surface, the approximate dimensions of the ganglion are $200 \times 500 \mu \mathrm{m}$. Therefore, the processes of many of these neurons ramified throughout the ganglion.

absolute; inputs that have a small postsynaptic effect might coexist within a domain dominated by another axon (see also Lichtman, 1980). Furthermore, the cell body may no longer act as a separate domain in the presence of dendrites. Finally, a single axon might fully innervate more than one domain of a cell.

Our suggestion that the cell body and each primary dendrite form domains that are largely constrained to 

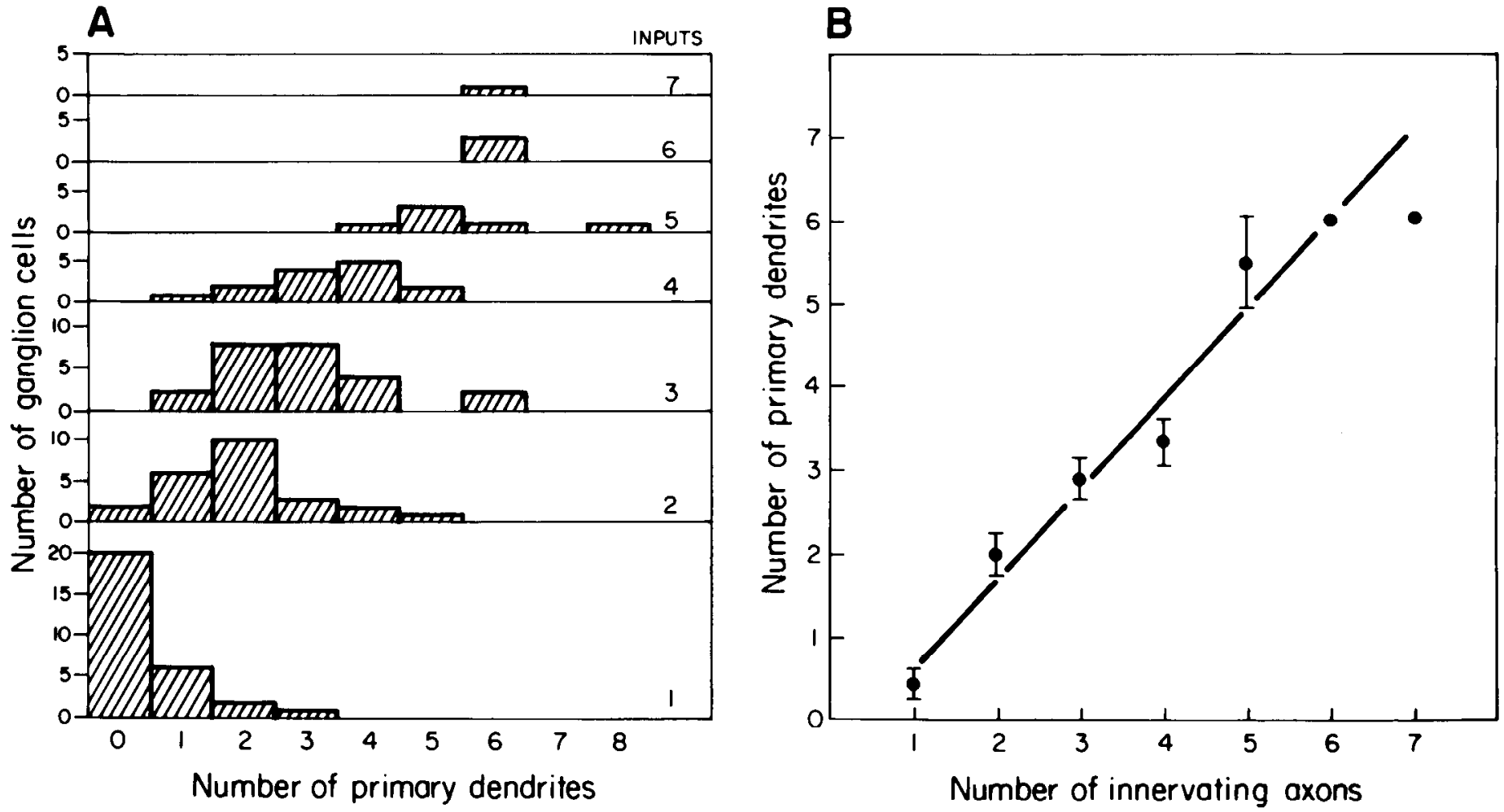

Figure 10. Relation of the number of primary dendrites to the number of different axons that innervated each ganglion cell. These data were obtained from the computer-assisted tracings and may differ slightly from the two-dimensional information presented in the camera lucida drawings. $A$, Distribution of cells with different numbers of primary dendrites; each histogram includes all of the cells receiving a given number of inputs (indicated on the right). $B$, Number of primary dendrites plotted as a function of the number of innervating axons. Each point represents the mean \pm the standard error (see Table I for $n$ values). The straight line was fitted to the data from the 101 cells studied by a least squares linear regression program. The slope of the line is 1.09 .

TABLE I

Total dendritic length, number of branch points, number of terminal dendritic segments, and equivalent cell body diameter of ganglion cells receiving innervation from different numbers of preganglionic axons

Equivalent diameters were calculated as the square root of the product of the major and minor axes. The values given are means \pm the standard error.

\begin{tabular}{|c|c|c|c|c|c|c|c|}
\hline & \multicolumn{7}{|c|}{ Number of Innervating Axons } \\
\hline & 1 & 2 & 3 & 4 & 5 & 6 & 7 \\
\hline $\begin{array}{l}\text { Total length of dendritic } \\
\text { arbor }(\mu \mathrm{m})\end{array}$ & $54 \pm 22$ & $321 \pm 53$ & $581 \pm 99$ & $1131 \pm 149$ & $1972 \pm 245$ & $2329 \pm 610$ & 2722 \\
\hline Number of branch points & $0.3 \pm 0.1$ & $1.3 \pm 0.4$ & $2.5 \pm 0.5$ & $6.4 \pm 1.3$ & $12.3 \pm 2.5$ & $11.7 \pm 7.5$ & 21.0 \\
\hline $\begin{array}{l}\text { Number of terminal seg- } \\
\text { ments }\end{array}$ & $0.7 \pm 0.3$ & $3.3 \pm 0.5$ & $5.3 \pm 0.7$ & $9.7 \pm 1.3$ & $17.8 \pm 2.9$ & $17.7 \pm 7.5$ & 27.0 \\
\hline $\begin{array}{l}\text { Equivalent cell body diam- } \\
\text { eter }\end{array}$ & $34.1 \pm 1.0$ & $34.3 \pm 0.9$ & $32.6 \pm 1.0$ & $41.0 \pm 1.8$ & $36.8 \pm 2.9$ & $34.0 \pm 1.0$ & 42.0 \\
\hline$\underline{n}$ & 29 & 24 & 24 & 14 & 6 & 3 & 1 \\
\hline
\end{tabular}

receive synapses from a single axon is somewhat difficult to reconcile with what is known about other classes of neurons. In an extreme example, each of thousands of dendritic spines on cerebellar Purkinje cells probably is contacted by a separate parallel fiber (Fox and Barnard, 1957; Eccles et al., 1967). Similarly, the idea of separate domains cannot apply without qualification to cells that receive different classes of inputs (e.g., excitatory and inhibitory) on the same dendrite. Nevertheless, the dramatic relation between innervation and cellular geometry in the ciliary ganglion is difficult to explain without recourse to the general idea of neuronal domains. 


\section{References}

Eccles, J. C., M. Ito, and J. Szentagothai (1967) The Cerebellum as a Neuronal Machine, Springer-Verlag, New York.

Fox, C. A., and J. W. Barnard (1957) A quantitative study of the Purkinje cell dendritic branchlets and their relationship to afferent fibres. J. Anat. 91: 299-313.

Hanker, J. S., P. E. Yates, C. B. Metz, and A. Rustioni (1977) A new specific, sensitive and non-carcinogenic reagent for the demonstration of horseradish peroxidase. Histochem. J. 9: 789-792.

Hume, R. I., and D. Purves (1980) Relation of multiple innervation to the geometry of rabbit ciliary ganglion cells. Soc. Neurosci. Abstr. 6: 186.

Johnson, D. A., and D. Purves (1980) Innervation of the ciliary ganglion in adult and neonatal rabbits. Soc. Neurosci. Abstr. 6: 185.

Johnson, D. A., and D. Purves (1981) Post-natal reduction of neural unit size in the rabbit ciliary ganglion. J. Physiol. (Lond.), in press.

Karnovsky, M. J. (1965) A formaldehyde-glutaraldehyde fixative of high osmolarity for use in electron microscopy. J. Cell Biol. 27: 137A.

Lichtman, J. W. (1977) The reorganization of synaptic connexions in the rat submandibular ganglion during post-natal development. J. Physiol. (Lond.) 273: 155-177.

Lichtman, J. W. (1980) On the predominantly single innervation of submandibular ganglion cells in the rat. J. Physiol. (Lond.) 302: $121-130$.
Lichtman, J. W., and D. Purves (1980) The elimination of redundant preganglionic innervation to hamster sympathetic ganglion cells in early post-natal life. J. Physiol. (Lond.) 301: 213-228.

McLachlan, E. (1974) The formation of synapses in mammalian sympathetic ganglia reinnervated with preganglionic or somatic nerves. J. Physiol. (Lond.) 237: 217-242.

Muller, K. J., and U. J. McMahan (1976) The shapes of sensory and motor neurones and the distribution of their synapses in ganglia of the leech: A study using intracellular injection of horseradish peroxidase. Proc. R. Soc. Lond (Biol.) 194: 481499.

Njå, A., and D. Purves (1977) Specific innervation of guinea-pig superior cervical ganglion cells by preganglionic fibres arising from different levels of the spinal cord. J. Physiol. (Lond.) 264: 565-583.

Purves, D. (1975) Functional and structural changes in mammalian sympathetic neurones following interruption of their axons. J. Physiol. (Lond.) 252: 429-463.

Purves, D., and J. W. Lichtman (1980) The elimination of some synaptic connections in autonomic ganglia during early postnatal life. In Ontogenesis and Functional Mechanisms of Peripheral Synapses. INSERM Symposium 13, J. Taxi, ed., pp. 15-26, Elsevier, New York.

Wann, D. F., T. A. Woolsey, M. L. Dierker, and W. M. Cowan (1973) An on-line digital-computer system for the semiaulomatic analysis of Golgi-impregnated neurons. IEEE Trans. Biomed. Eng. 20: 233-247. 